\title{
U.S. Geological Survey Response to White-Nose Syndrome in Bats
}

\section{Overview}

Since its discovery in 2007, the fungal disease known as white-nose syndrome (WNS) has killed more than six million bats. Ten of 47 bat species have been affected by WNS across 32 States and 5 Canadian Provinces. The cold-growing fungus (Pseudogymnoascus destructans) that causes WNS infects skin covering the muzzle, ears, and wings of hibernating bats. The fungus erodes deep into the vitally important skin of bat wings and fatally disrupts hibernation of bats through physical damage

and energy depletion as they try to cope with infection.

U.S. Geological Survey (USGS) science has been critical in identifying the causal fungus, characterizing the effects of WNS, and tracking the fungus as it rapidly spreads through many populations of bats in North America. Early USGS research enhanced our understanding of how WNS affects individual bats and how the fungus persists in the environment. Today, USGS scientists are engaged in a nationwide response to WNS, in close coordination with our partners at the U.S. Fish and Wildlife Service (USFWS), National Park Service (NPS), and U.S. Forest Service (USFS). 


\section{Importance of Bats}

Bats, the only mammal capable of true flight, eat mind-boggling quantities of insects, including those that damage crops and forests (corn earworm moth, emerald ash borer beetle) and those that carry diseases (mosquitoes). USGS research indicates that bats likely save U.S. farmers billions of dollars each year in pest suppression simply by doing what they naturally do in most places-eating insects. In subtropical and tropical areas, bats also play major roles in pollinating and dispersing the seeds of many important species of plants.

A female yuma myotis (Myotis yumanensis) pursuing a moth on the wing. Bats catch their prey in the wing membrane and then scoop it into their mouth (digital composite).

Copyright Michael Durham (used with permission).
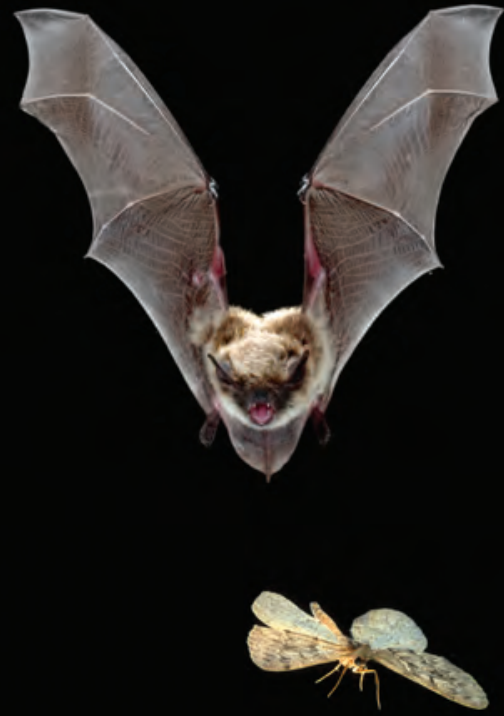

\section{Early Detection Tools and Mapping the Spread of WNS}

The USGS National Wildlife Health Center (NWHC) (Madison, Wisconsin) serves as the reference laboratory for WNS detections in the United States, analyzing one to two thousand samples each year from across the country. NWHC scientists work with partners to strengthen and enhance laboratory and field methods for detecting WNS and the causative fungus.

The USGS Fort Collins Science Center (FORT) (Fort Collins, Colorado) manages the national WNS website (https://www.whitenosesyndrome.org/), which includes static and dynamic maps of the spread of WNS in

North America. These maps provide up-to-date information for natural resource managers to guide targeted surveillance or control efforts along the leading edge of disease spread.

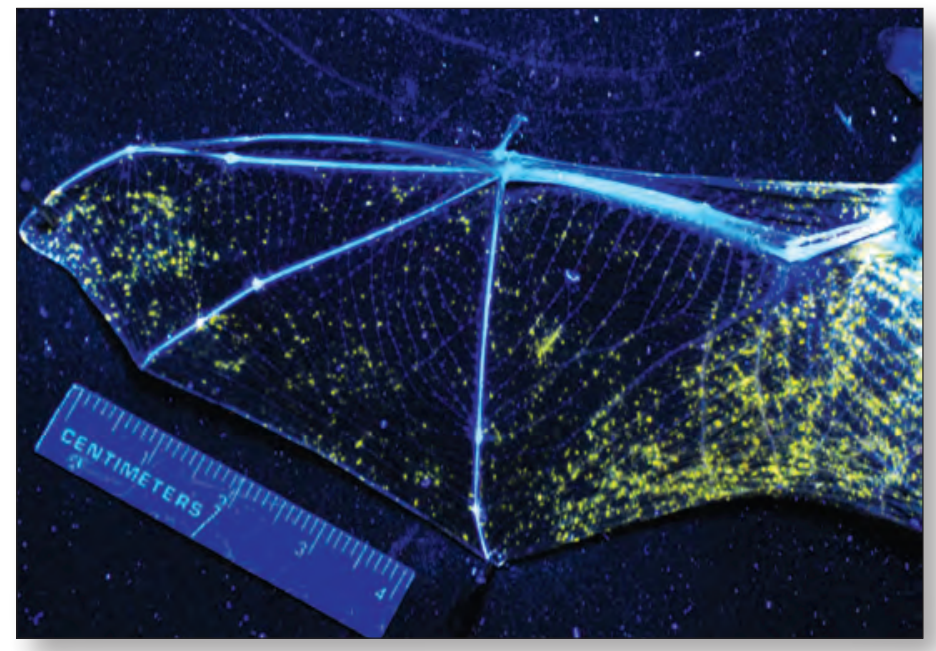

Figure 2. Wing of a bat affected by white-nose syndrome (WNS) under ultraviolet light. Areas affected by WNS appear yellow-orange under ultraviolet light. Use of ultraviolet light provides a useful tool in field and rehabilitation settings to screen bats for signs suggestive of WNS. Additional laboratory diagnostic testing is required to confirm a WNS diagnosis. (Modified from Turner and others, 2014.) 


\section{Monitoring Bats}

The USGS Virginia Cooperative Fish and Wildlife Research Unit (Blacksburg, Virginia) is assessing the performance of acoustic bat monitoring tools and methods to support the USFWS and other Federal and State agency guidance on bat monitoring for regulatory assessment.

The USGS FORT, Upper Midwest Environmental Sciences Center (UMESC) (La Crosse, Wisconsin), and Northern Rocky Mountain Science Center (NOROCK) (Bozeman, Montana) have taken the lead in coordinating the North American Bat Monitoring Program (NABat, https://nabatmonitoring.org), a long-term monitoring program that includes USFS, USFWS, NPS, U.S. Department of Defense, Canadian Wildlife Service, Canadian Wildlife Health Cooperative, Bat Conservation International, and Wildlife Conservation Society Canada.

Figure 3 (right). Endangered Indiana bats (Myotis sodalis) in New York with forearm bands and radio transmitters. Photograph by Tomas Nocera.
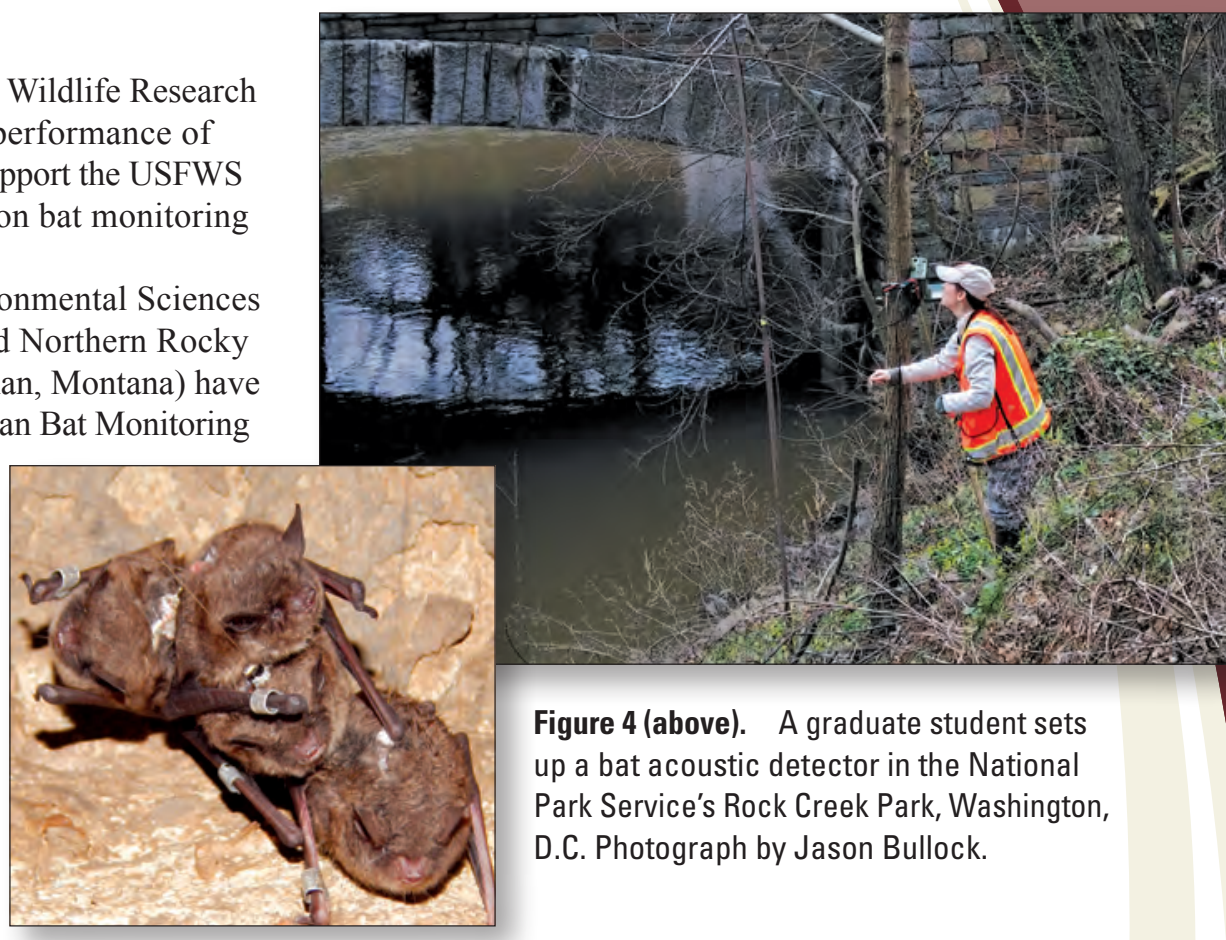

Figure 4 (above). A graduate student sets up a bat acoustic detector in the National Park Service's Rock Creek Park, Washington, D.C. Photograph by Jason Bullock.

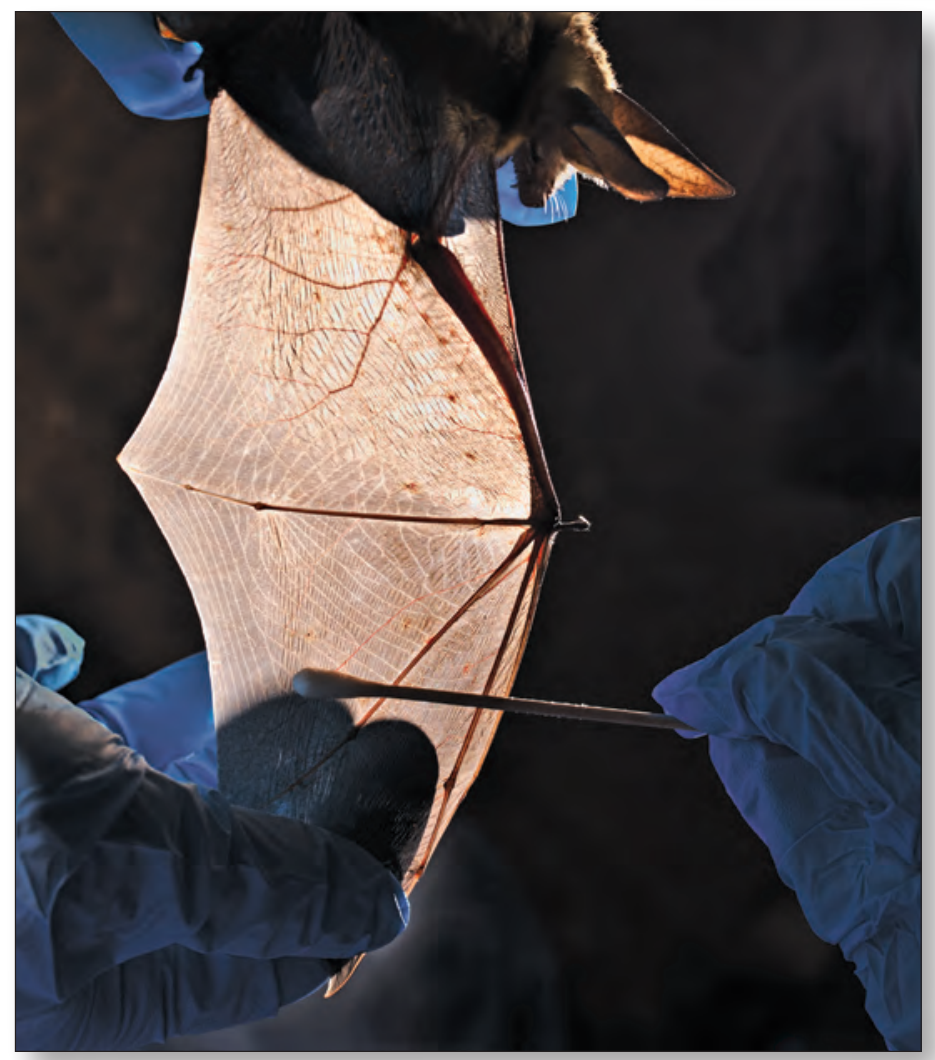

\section{Developing Treatments for WNS}

Scientists at the USGS NWHC and FORT are investigating the fungi and bacteria on bat skin (microbiome) to identify natural defenses and potential control mechanisms.

The USGS NWHC has expertise in vaccine development for diseases such as sylvatic plague in prairie dogs. That technology is being used to investigate the potential for a WNS vaccine. As a proof-of-concept, in collaboration with the Centers for Disease Control and Prevention, the USGS completed preliminary trials of a bat rabies vaccine in which more rabies-vaccinated bats survived the virus than unvaccinated bats.

Figure 5 (above). Pallid bat (Antrozous pallidus) being swabbed. Photograph by Kenneth Ingham.

Figure 6 (right). The mycobiome from a resistant bat species growing in culture (a swab from the bat's skin was streaked across the agar surface in lines). Pink and white structures are colonies of different yeast species from the wing of the bat growing on laboratory medium. Photograph by National Wildlife Health Center.

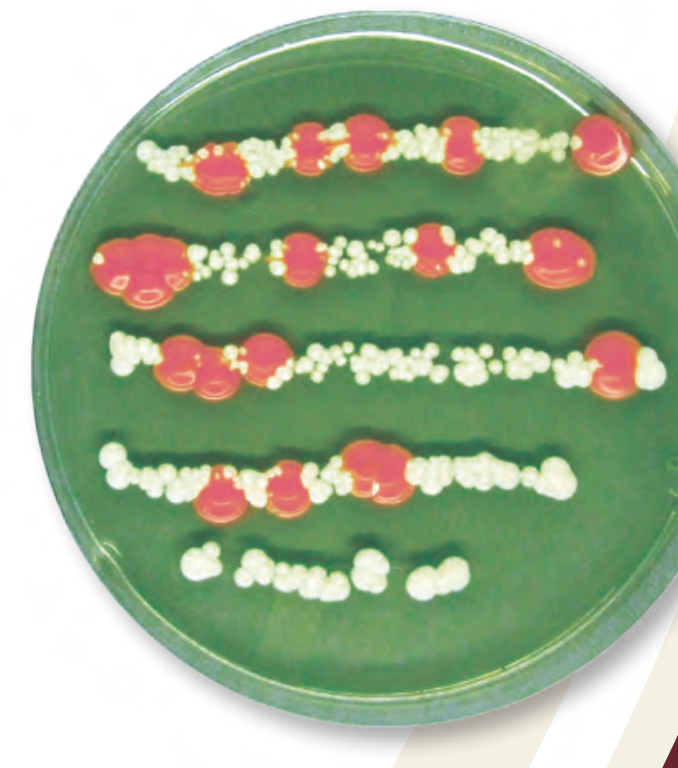




\section{Assessing the Impact of WNS on Bat Populations}

Scientists at the USGS UMESC and NWHC are developing tools to assess the impact of WNS on the viability of bat populations and estimate recovery potential. BatTool, a statistical package (https://github.com/USGS-R/BatTool), was developed to help decision makers understand how the combined effects of WNS and other stressors, such as wind energy development, may impact specific bat populations.

Since WNS was discovered, scientists at USGS FORT have been investigating why certain populations of bats are more susceptible to WNS than others. In addition to studying how bats survive WNS, this work can help identify populations most in need of treatment or other interventions.

Figure 7 (right). Thermal image of Indiana bats (Myotis sodalis) grouped for warmth (bright areas). Photograph by Paul Cryan.

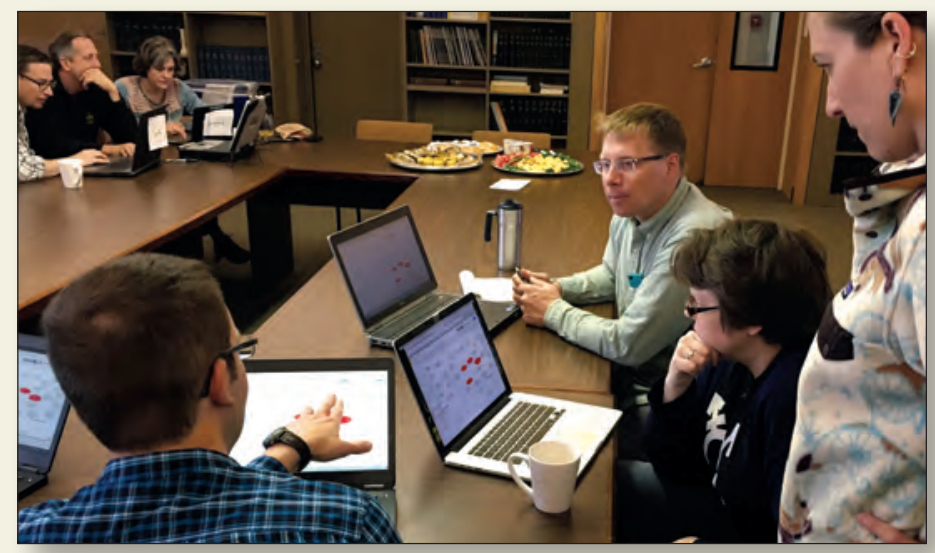

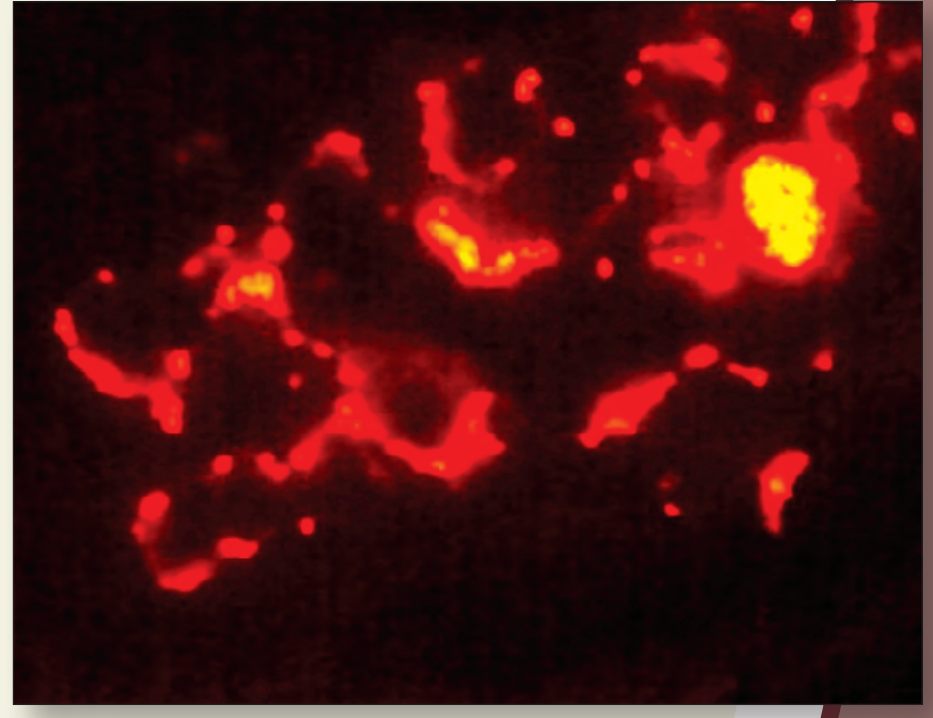

\section{Facilitating Adaptive WNS Management}

USGS scientists at Patuxent Wildlife Research Center are working with Federal and State wildlife partners to help identify management actions that maximize bat persistence and reduce the spread of WNS, taking into consideration the timing of these actions based on occurrence of the disease (WNS free area, WNS established area, leading edge).

Figure 8. The U.S. Fish and Wildlife Service (USFWS), U.S. Geological Survey (USGS), and Pennsylvania State University, in collaboration with the Cranbrook Institute and Organization for Bat Conservation, convened a white-nose syndrome (WNS) science synthesis workshop in Bloomfield Hills, Michigan. Diverse scientific expertise was utilized to identify information gaps, management interventions, and novel actions to respond to WNS. Photograph by Evan Grant.

The fungus causing WNS has been detected on Eastern red bats (Lasiurus borealis). Photograph by Alexander Silvis.

\section{n}

